J. Lake Sci. (湖泊科学), 2019, 31(3): 646-655

DOI 10. 18307/2019. 0304

(C) 2019 by Journal of Lake Sciences

\title{
太湖流域太浦河周边区域突发水污染潜在风险评估
}

\author{
周宏伟 ${ }^{1}$, 黄佳聪 $^{2 * *}$, 高俊峰 $^{2 * *}$, 间人华 ${ }^{2}$, 彭炎梅 $^{1}$, 曹菊萍 $^{1}$, 尚㻇仪 ${ }^{1}$ \\ (1:太湖流域管理局水利发展研究中心,上海 200434) \\ (2: 中国科学院南京地理与湖泊研究所,中国科学院流域地理学重点实验室,南京 210008)
}

\begin{abstract}
摘 要: 太浦河是太湖流域重要跨省界河流,沿岸区域污染源众多,下游分布重要水源地, 存在突发水污染潜在风险, 迫 切需要开展区域污染源潜在风险评估, 为突发水污染事件的风险防控提供科学依据. 本研究通过太浦河周边区域的污染 源调研, 明确污染源的空间分布与污染源强, 确定评估区域的主要污染物 (化学需氧量、氨氮、锑、重金属铬、油品、危险化 学品), 综合考虑污染源、河流水文、沿岸社会经济等因素, 笁选突发水污染潜在风险评估指标, 构建评估指标体系, 评估 突发水污染事件的综合风险, 识别太浦河周边区域的主要突发水污染潜在风险源. 研究结果表明: 太浦河周边区域的高 突发水污染风险区呈现片状或斑块状分布, 主要包括大型污水处理厂区域、大型工业企业区域、加油站和危险化学品仓 库集中分布区、太浦河沿岸工业企业区域、水源地周边工业企业区域, 总面积为 $22 \mathrm{~km}^{2}$, 占太浦河污染源风险评估范围总 面积的 $1.4 \%$,是突发水污染事件防控的重点区域.
\end{abstract}

关键词: 太浦河;突发水污染; 风险评估

\section{Potential risk assessment for water pollution accident in Taipu River region, Taihu Basin}

ZHOU Hongwei $^{1}$, HUANG Jiacong ${ }^{2 * *}$, GAO Junfeng ${ }^{2 * *}$, YAN Renhua ${ }^{2}$, PENG Yanmei $^{1}$, CAO Juping ${ }^{1} \&$ SHANG Zhaoyi ${ }^{1}$

(1: Development and Research Center of Water Conservancy, Taihu Basin Authority, Shanghai 200434, P.R. China)

(2: Key Laboratory of Watershed Geographic Sciences, Nanjing Institute of Geography and Limnology, Chinese Academy of Sciences, Nanjing 210008, P.R.China)

Abstract: River Taipu in China is an important river across three provinces with considerable pollution sources in its surrounding regions. These pollution sources pose threats for several drinking water intakes located at the lower reach of the river. Assessing the potential risk of water pollution accident for Taipu River can well support our controlling for water pollution accident. This study investigated the distribution and intensity of the pollution sources surrounding Taipu River. Chemical oxygen demand, ammonia, antimony, heavy metal chromium, oils and hazardous chemicals were identified as the critical pollutions for the river. By considering the factors related to pollution sources, river hydrology, social economy, critical indictors were selected for developing assessment index for risk assessment of water pollution accident. The high-risk area in the study area was identified. The assessment results showed that the high-risk region has an area of $22 \mathrm{~km}^{2}(1.4 \%)$, mostly located at the region with large wastewater treatment plant or industrial factories, the region with many gas stations or warehouses of hazardous chemicals, the nearshore region with industrial factories, and the near region close to drinking water intakes with industrial factories. These regions are worth our concern in the risk controlling for water pollution accident

Keywords: River Taipu; water pollution accident; risk assessment

突发水污染事件是指由人为或者自然灾害引起的、在短时间内大量污染物进人水体或供水管网,使水 质迅速恶化的水污染事件 ${ }^{[1]}$. 近年来, 我国突发性水污染事件频发, 2004-2015 年突发公共卫生事件信息管

* 国家水体污染控制与治理科技重大专项 (2017ZX07301-001-02) 和中国科学院南京地理与湖泊研究所 “一三五” 战 略发展规划项目 (NIGLAS2018GH06) 联合资助. 2018-07-28 收稿;2018-10-28 收修改稿. 周宏伟(1973 ), 男, 硕 士研究生,高级工程师; E-mail: zhouhw999@ sohu.com.

** 通信作者;E-mail: jchuang@ niglas.ac.cn, gaojunf@ niglas.ac.cn. 
理系统共报告 126 起水污染事件, 累计病例数 16571 例 ${ }^{[1]}$. 突发水污染事件主要包括溢油事件、有毒化学品 泄露事件、非正规途径大量排放污水等, 不仅威胁当地水质安全、破坏水生态环境、造成巨大经济损失, 而且 严重干扰正常社会生产生活,甚至导致社会恐慌 ${ }^{[2-6]}$.

全面开展突发水污染研究已成为水环境管理的迫切需求,国内外学者开展了突发水污染事件的污染溯 源、影响范围预测、应急处置等方面的研究 ${ }^{[6-13]}$; 其中王家彪等采用耦合概率密度方法开发了突发水污染溯 源模型,并应用于推测污染源位置、污染物排放强度与排放时间 ${ }^{\left[{ }^{[7]}\right.}$; 陶亚等 ${ }^{[6]}$ 、房彦梅等 ${ }^{[13]}$ 、Grifoll 等 ${ }^{[11]}$ 、van Mazijk 等 ${ }^{[12]}$ 通过构建水动力一污染物输移过程模型, 模拟了水体污染物的迁移转化过程, 分析识别污染物 扩散的主要驱动要素,并提出优化的应急控制策略; 突发水污染的风险评估工作开展较少 ${ }^{[14-15]}$.

太浦河沿途跨越江苏省、浙江省和上海市的 15 个乡镇, 在浙江省嘉兴市、上海市西南等地区分布多个 重要供水水源地, 两岸支流与湖荡众多, 是典型的平原河网地区. 同时, 该地区经济发达, 河道航道密集, 工 业企业与污水处理厂众多, 加油站与码头遍布, 存在发生突发性水污染的潜在风险, 对太浦河供水与生态系 统有一定安全隐患. 尽管太浦河水环境已广受关注, 但结合陆域突发水污染潜在风险源的空间分布, 开展突 发水污染的潜在风险研究不多, 本研究基于 2017 年的污染源调研数据, 结合平原区水文规律与水源地分 布, 构建了突发水污染潜在风险评估指标体系, 开展了突发水污染潜在风险评估, 分析了突发水污染潜在风 险的空间特征,识别了突发水污染的高风险区域,研究成果有利于提升突发水污染事件的防控水平与应急 处置能力, 是突发水污染风险管理的迫切需求.

\section{1 研究区域与数据}

\section{1 研究区域}

太浦河是在天然湖荡基础上于 1958 年开挖的人工河流, 西起东太湖 (江苏省吴江市七都镇), 东至上海 市南大港接西泖河人黄浦江, 全长 $57.6 \mathrm{~km}$, 其中江苏吴江境内 $40.4 \mathrm{~km}$, 浙江嘉善境内 $2.0 \mathrm{~km}$, 上海青浦境内 $15.2 \mathrm{~km}$ (图 1); 太浦河沿途跨越江苏省、浙江省和上海市的 15 个乡镇, 兼有防洪、排涝、供水、灌溉、航运等 多种功能. 综合考虑太浦河周边水系的水文条件, 结合太浦河水质保护目标, 确定太浦河周边区域突发水污

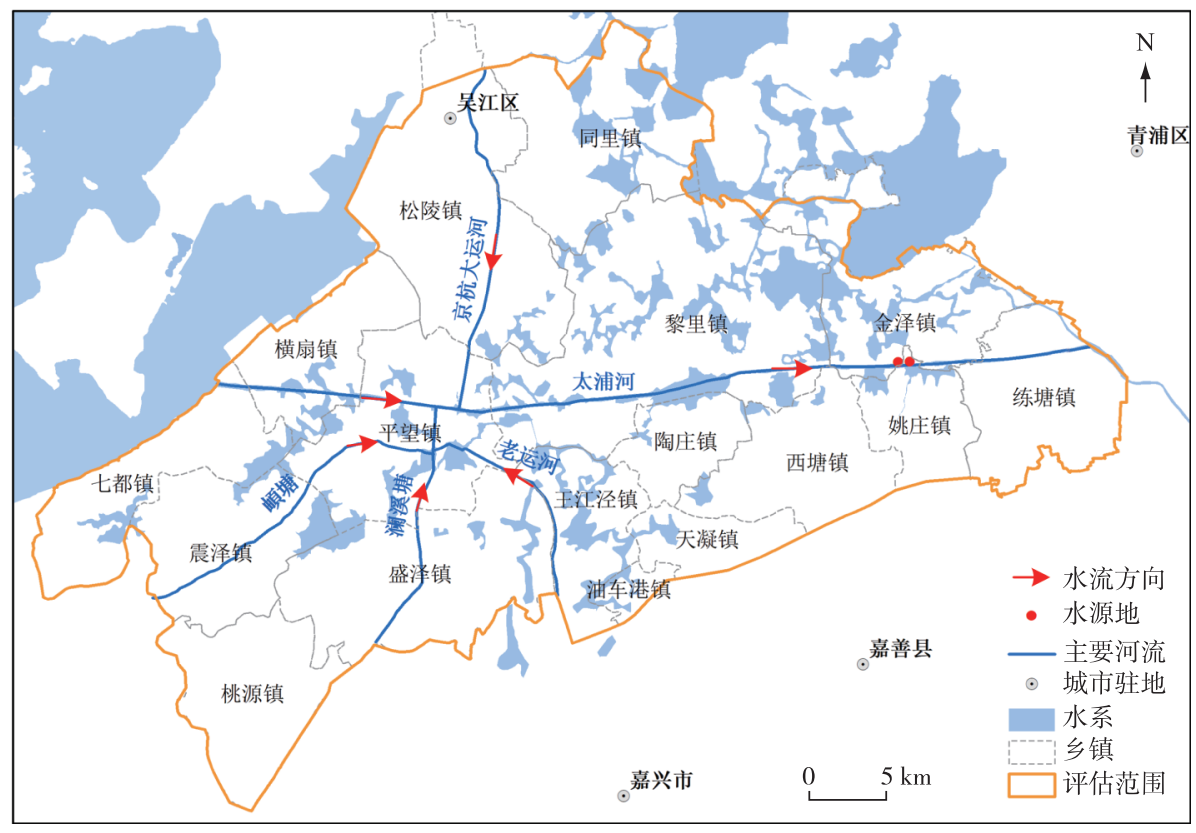

图 1 太浦河突发水污染潜在风险评估范围

Fig.1 Location of Taipu River region for potential risk assessment of water pollution accident 
染潜在风险的评估范围, 西以东太湖东部大堤为界, 北以吴淞江、急水港为界, 东以拦路港、西泖港为界, 南 以红旗塘、浙沪交界河道为界, 涉及行政区包括江苏省苏州市吴江区、浙江省嘉兴市嘉善县与秀洲区、上海 市青浦区, 总面积为 $1624.0 \mathrm{~km}^{2}$. 本研究采用正方形网格剖分研究区范围, 网格的空间分辨率为 $1000 \mathrm{~m} \times$ $1000 \mathrm{~m}$, 包括 1624 个网格单元.

\section{2 数据}

本研究数据包括评估范围内的污染源、人口、经济、土地利用数据, 人口数据来源为第六次全国人口普 查; 经济数据为乡镇 GDP,采用调研方法获取; 土地利用数据采用 GoogleEarth 来源的 2017 年遥感影像解译 获取; 污染源数据主要以第一次全国污染源普查的成果为基础, 采用相关部门 (环保、水利、城建等)资料收 集、现场调研与专家咨询相结合的手段更新污染源数据,获取研究区域 2017 年的突发水污染潜在风险源 ( 图 2), 主要包括:


图 2 太浦河突发水污染源分布:工业企业 (a)、污水处理厂 (b)、加油站 $(c)$ 、码头 (d)、危险化学品仓库 (e)

Fig. 2 Location of pollution sources for water pollution accident in Taipu River region: (a) Industrial factories;

(b) Wastewater treatment plant; (c) Gas stations; (d) Docks; (e) Warehouses of hazardous chemicals 
1) 483 家工业企业: 研究区内的工业企业废水多数排人污水厂处理, 日常运行中, 对水环境影响很小, 但 由于本研究评估突发水污染潜在风险, 因此选择作为污染源, 具体信息包括化学需氧量年排放量 $(\mathrm{t})$ 、氨氮 年排放量 $(\mathrm{t}) 、$ 锑年排放量 $(\mathrm{kg}) 、$ 重金属铬年排放量 $(\mathrm{kg})$.

2) 41 家污水处理厂: 污染处理厂主要处理工业废水与生活污水,污染源信息包括化学需氧量年排放量 $(\mathrm{t}) 、$ 氨氮年排放量 $(\mathrm{t})$.

3) 主要水系周边 79 家加油站: 主要污染物为油品, 污染源信息包括油罐总容积 $\left(\mathrm{m}^{3}\right)$.

4) 99 个码头: 主要污染物为油品与危险化学品, 污染源信息包括货运类型、占地面积 $\left(\mathrm{m}^{2}\right)$.

5) 83 个危险化学品仓库: 主要污染物为危险化学品,污染源信息包括工业废水年排放量 $(\mathrm{t})$.

\section{2 突发水污染潜在风险评估方法}

\section{1 评估指标体系构建}

国内外已针对河流与海洋等水生态系统开展了大量突发水污染风险评估工作, 尽管方法有所差异, 但 主要从风险源、风险受体来阐明风险评估的内涵与发生机理 ${ }^{[15-19]}$. 不同类型的风险受体 (生境) 对外界干扰 的抵抗能力是不同的, 有些风险受体较为脆弱, 对外界干扰敏感, 在风险源的作用下极易受到损害, 而另一 些生境抗逆性能力强, 可直接影响到风险源的破坏力, 在相同的风险源作用下仍能够保持其基本的功能, 即 相同强度的同一风险源作用于不同的风险受体类型, 可能对整个区域的结构和功能产生不同强度的危害. 因此, 风险评估需要定量潜在风险源危害性、风险受体敏感性、风险受体潜在损失度, 计算公式如下 ${ }^{[14,20]}$ :

$$
R=R H \cdot R S \cdot S L
$$

式中, $R$ 为单一污染物风险, $R H 、 R S 、 S L$ 分别为该类潜在风险源危害性、风险受体敏感性、风险受体潜在损 失度.

基于目标层一要素层一指标层多层次框架结构, 从潜在风险源危害性、风险受体敏感性、风险受体潜在 损失度 3 方面构建评估指标体系 (表 1)，指标选取方法说明如下：

1) 潜在风险源危害性与污染源源强大小直接相关. 根据污染源分布现状 (图 2), 太浦河沿岸污染源主 要包括 6 种污染物: 化学需氧量、氨氮、锑、重金属铬、油品、危险化学品, 因此选择上述污染物开展突发水污 染风险评估;污染物来源包括工业企业、污水处理厂、加油站、码头、危险化学品仓库, 污染源的潜在源强采 用规模表征,源强越大,其危害性越大.

2) 风险受体敏感性内涵是太浦河对污染源发生突发水污染事件的敏感程度,因此重点考虑两方面要 素:污染源与太浦河的输移距离、污染源与太浦河取水口的距离. 如果距离大, 则污染源发生突发水污染事 件时, 污染物需要较长时间才能输移到太浦河/取水口, 而在输移过程中污染物可能被稀释、降解, 可认为风 险受体敏感性较小.

表 1 太浦河突发水污染潜在风险评估指标体系

Tab.1 Index system for potential risk assessment of water pollution accident in Taipu River region

\begin{tabular}{ccc}
\hline 目标层 & 要素层 & 指标层 \\
\hline 污染风险指数 & 潜在风险源危害性 & 油品存储量 \\
& & 危险化学品存储量 \\
化学需氧量年排放量 \\
氨氮年排放量 \\
重金属铬年排放量 \\
锑年排放量 \\
& 风险受体敏感性 & 风险受体潜在损失度 \\
& & 污染源与太浦河的输移距离 \\
& 污染源与太浦河取水口的距离 \\
& 人口 \\
& 经济发展 \\
土地利用
\end{tabular}


3) 风险受体潜在损失度主要表征发生突发水污染事件后造成的损失,一般认为社会经济条件可以反映 区域社会系统对灾害的敏感度,因此采用人口、经济发展、土地利用表征, 反映了污染风险源的下游地区城 镇化和土地开发利用强度. 下游土地开发强度越大, 说明水污染事件造成的经济和社会潜在损失越大.

\section{2 评估指标计算}

2.2.1 潜在风险源危害性 基于污染源 (油品、危险化学品、化学需氧量、氨氮、重金属铬、锑) 源强数据,采用 数据归一化处理方法,分别计算评估范围内不同网格单元的潜在风险源危害性,计算公式为:

$$
R H_{i x}^{*}=\frac{R H_{i x}-R H_{\text {Min }}}{R H_{\text {Max }}-R H_{\text {Min }}}
$$

式中, $R H_{i x}^{*}$ 为 $i$ 网格污染物 $x$ 的潜在风险源危害性, $R H_{i x}$ 为 $i$ 网格的污染物 $x$ 的排放源强, $R H_{\text {Min }}$ 为太浦河污染 源风险评估范围的污染物 $x$ 风险源源强的最小值, $R H_{\text {Max }}$ 为太浦河污染源风险评估范围的污染物 $x$ 风险源源 强的最大值. $R H_{i x}^{*}$ 是无量纲化的污染物排放源强, 取值范围为 $0 \sim 1.0$, 数值越大表明该网格排放该类污染物 的总量越大, 危害性越大.

2.2.2 风险受体敏感性 本研究的风险受体为太浦河, 但水源地是太浦河中的敏感区域, 因此风险受体敏感 性考虑了两方面要素, 即污染源与太浦河的输移距离、污染源与太浦河取水口的距离, 分别采用污染物空间 输移距离指数、水源地敏感性指数表征, 计算过程说明如下:

根据污染物空间输移距离和水源地敏感性指数计算, 计算公式为:

$$
R S_{i}^{*}=\frac{S D I_{i}^{*}+W S I_{i}^{*}}{2}
$$

式中, $R S_{i}$ 为 $i$ 网格的风险受体敏感性, 数值越大, 表明太浦河对该网格单元发生的突发水污染事件越敏感; $S D I_{i}^{*}$ 和 $W S I_{i}^{*}$ 分别为 $i$ 网格的污染物空间输移距离指数和水源地敏感性指数, 计算过程分别说明如下:

1) $S D I_{i}^{*}$ 为污染物输移到太浦河空间距离的归一化数值, 计算公式为:

$$
S D I_{i}^{*}=1-\frac{S D I_{i}-S D I_{\text {Min }}}{S D I_{\text {Max }}-S D I_{\text {Min }}}
$$

式中, $S D I_{i}$ 为 $i$ 网格污染物输移到太浦河的空间距离, $\mathrm{km}$; $S D I_{\text {Min }}$ 为太浦河污染源风险评估范围所有网格单 元 $S D I_{i}$ 的最小值, $\mathrm{km} ; S D I_{\text {Мах }}$ 为太浦河污染源风险评估范围所有网格单元 $S D I_{i}$ 的最大值, $\mathrm{km}$.

2) $W S I_{i}^{*}$ 为网格到最近水源地直线距离的归一化数值, 计算公式为:

$$
W S I_{i}^{*}=1-\frac{W S I_{i}-W S I_{\text {Min }}}{W S I_{\text {Max }}-W S I_{\text {Min }}}
$$

式中, $W S I_{i}^{*}$ 为 $i$ 网格的水源地敏感性指数; $W S I_{i}$ 为 $i$ 网格到最近水源地的直线距离, $\mathrm{km}$; $W S I_{\mathrm{Min}}$ 为太浦河污 染源风险评估范围网格单元到最近水源地距离的最小值, $\mathrm{km}$; WSI $I_{\text {Max }}$ 为太浦河污染源风险评估范围网格单元 到最近水源地距离的最大值, $\mathrm{km}$.

2.2.3 风险受体潜在损失度 风险受体潜在损失度与人口状况、土地利用程度、经济发展等相关, 选取下游人 口数量、下游建设用地比重、下游人均 GDP 等相关指标, 计算风险受体潜在损失度:

$$
S L_{i x}^{*}=\beta_{1} \cdot T P_{i x}^{*}+\beta_{2} \cdot C P_{i x}^{*}+\beta \cdot G_{i x}^{*}
$$

式中, $S L_{i x}^{*}$ 为 $i$ 网格污染物 $x$ 的下游潜在损失度; $T P_{i x}^{*}$ 为 $i$ 网格污染物 $x$ 的下游人口数量指数; $C P_{i x}^{*}$ 为 $i$ 网格 污染物 $x$ 的下游建设用地面积指数; $G_{i x}^{*}$ 为 $i$ 网格污染物 $x$ 的下游人均 GDP 指数; $\beta_{1} 、 \beta_{2}$ 和 $\beta_{3}$ 分别为 $T P_{i x}^{*}$ 、 $C P_{i x}^{*}$ 和 $G_{i x}^{*}$ 的相对权重, 分别取 $0.4 、 0.4$ 和 $0.2 ; T P_{i x}^{*}$ 为下游人口数量指数, 为下游人口数量的无量纲处理, 取 值范围为 $0 \sim 1$, 数值越大, 表明下游人口越多, 发生突发水污染事件时, 对太浦河的潜在损失度就越大; $C P_{i x}^{*}$ 为下游建设用地面积, 为下游建设用地比例的无量纲处理, 取值范围为 $0 \sim 1$, 数值越大, 表明下游城镇比例 越高; $G P_{i x}^{*}$ 为下游人均 GDP 指数, 为下游人均 GDP 的无量纲处理, 反映污染风险源的下游地区总体经济发 展水平, 取值范围为 $0 \sim 1$, 数值越大, 表明该地区的经济越发达, 受突发水污染事件的潜在损失度越大.

\section{3 污染风险计算与等级划分}

2.3.1 单一污染物风险指数计算 根据公式 (1), 评估范围内的网格单一污染物风险指数可采用以下公式 计算: 


$$
R_{i}^{x}=R H_{i x}^{*} \cdot R S_{i}^{*} \cdot S L_{i x}^{*}
$$

式中, $R_{i}^{x}$ 为 $i$ 网格的单一污染物 $(x)$ 风险指数, $R H_{i x}^{*}$ 为 $i$ 网格污染物 $x$ 的风险源源强指数, $R S_{i}^{*}$ 为太浦河对 $i$ 网格污染物的敏感性指数, $S L_{i x}^{*}$ 为 $i$ 网格污染物 $x$ 的风险受体潜在损失度指数.

2.3.2 综合风险指数计算 基于 6 种污染物 (油品、危险化学品、化学需氧量、氨氮、铇、重金属铬) 的风险指 数计算结果, 采用权重法计算网格单元的突发水污染综合风险指数 ${ }^{[16]}$ :

$$
R_{i}=\sum_{x=1}^{n} R_{i}^{x} \cdot w_{x}
$$

式中, $R_{i}$ 为 $i$ 网格的综合风险指数, $R_{i}^{x}$ 为 $i$ 网格的污染物 $x$ 的风险指数, $w_{x}$ 为污染物 $x$ 的权重系数, $n$ 为污染 物数量 $(n=6)$. 污染物权重系数的确定主要依据各污染物造成水质污染的相对危害性, 并通过专家咨询调 整权重系数, 最终确定油品、危险化学品、化学需氧量、氨氮、铇和重金属铬的权重分别为 $0.2 、 0.2 、 0.1 、 0.1$ 、 0.2 和 0.2 .

2.3.3 综合风险等级划分 基于突发水污染的综合风险指数计算结果,划分突发水污染的综合风险等级;根 据综合风险指数的定义, 采用常用的数值排序法, 结合专家经验最终确定风险等级, 即风险指数数值越大, 定义的风险级别越高, 为便于风险分析, 将突发水污染的综合风险等级划分为 5 级 ( I 级、II 级、III 级、IV 级 和 $\mathrm{V}$ 级)，不同风险等级及其区域特征说明见表 2 .

表 2 太浦河污染源综合风险等级划分

\begin{tabular}{|c|c|c|c|}
\hline 风险等级 & 风险指数 & 风险等级说明 & 风险区域特征 \\
\hline $\mathrm{I}$ 级 & 0 & 突发水污染风险极低 & $\begin{array}{l}\text { 该区域无加油站、危险化学品仓库、码头、工业企业、污水 } \\
\text { 处理厂 }\end{array}$ \\
\hline II 级 & $0 \sim 0.03$ & 突发水污染风险较低 & $\begin{array}{l}\text { 该区域分布少量加油站、危险化学品仓库、码头、工业企 } \\
\text { 业、污水处理厂中的一种或多种污染源组合 }\end{array}$ \\
\hline III 级 & $0.03 \sim 0.05$ & 突发水污染风险中度 & $\begin{array}{l}\text { 该区域有较多的加油站、危险化学品仓库、码头、工业企 } \\
\text { 业、污水处理厂中的一种或多种污染源组合 }\end{array}$ \\
\hline IV 级 & $0.05 \sim 0.10$ & 突发水污染风险较高 & $\begin{array}{l}\text { 该区域有很多的加油站、危险化学品仓库、码头、工业企 } \\
\text { 业、污水处理厂中的一种或多种污染源组合 }\end{array}$ \\
\hline $\mathrm{V}$ 级 & $>0.10$ & 突发水污染风险高 & $\begin{array}{l}\text { 该区域有大型加油站、危险化学品仓库、码头、工业企业、 } \\
\text { 污水处理厂中的一种或多种污染源组合,或者与太浦河或 } \\
\text { 水源地距离很近,下游经济社会潜在损失度高 }\end{array}$ \\
\hline
\end{tabular}

Tab.2 Division of risk levels for water pollution accident in Taipu River region

\section{3 结果与分析}

\section{1 风险受体敏感性与潜在损失度}

风险受体敏感性的总体规律是从上游到下游呈现不断升高的趋势, 主要是由于上游污染物输移到下游 所需时间较长, 因此上游区域的敏感性数值较低; 与之相反, 风险受体潜在损失度从上游到下游呈现不断下 降的趋势, 主要原因是上游污染物可能影响到区域范围较大, 因此潜在损失度较大 (图 3).

\section{2 单一污染物风险}

太浦河污染风险评估范围内, 油品、危险化学品、化学需氧量、氨氮、锑、重金属铬的风险指数存在显著 空间差异 (图 4) , 分类说明如下:

1) 油品: 大型的加油站和建材码头主要分布在京杭大运河周边的松陵镇、五河 (太浦河、京杭大运河、頔 塘、㴹溪塘、老运河) 交汇处的平望镇, 且松陵镇位于太浦河周边水系的上游, 风险受体潜在损失度较大, 因 此两镇的油品风险指数显著高于其他乡镇. 在黎里镇太浦河沿岸分布的加油站区域, 距太浦河和水源地均 较近,也分布有高值网格.

2) 危险化学品:危险化学品仓库和危险化学品专用运输码头集中分布于頔塘水系, 导致该水系距太浦 河比较近的平望镇成为危险化学品风险高值区. 同里镇也分布有大型的危险化学品仓库, 出现部分高值 

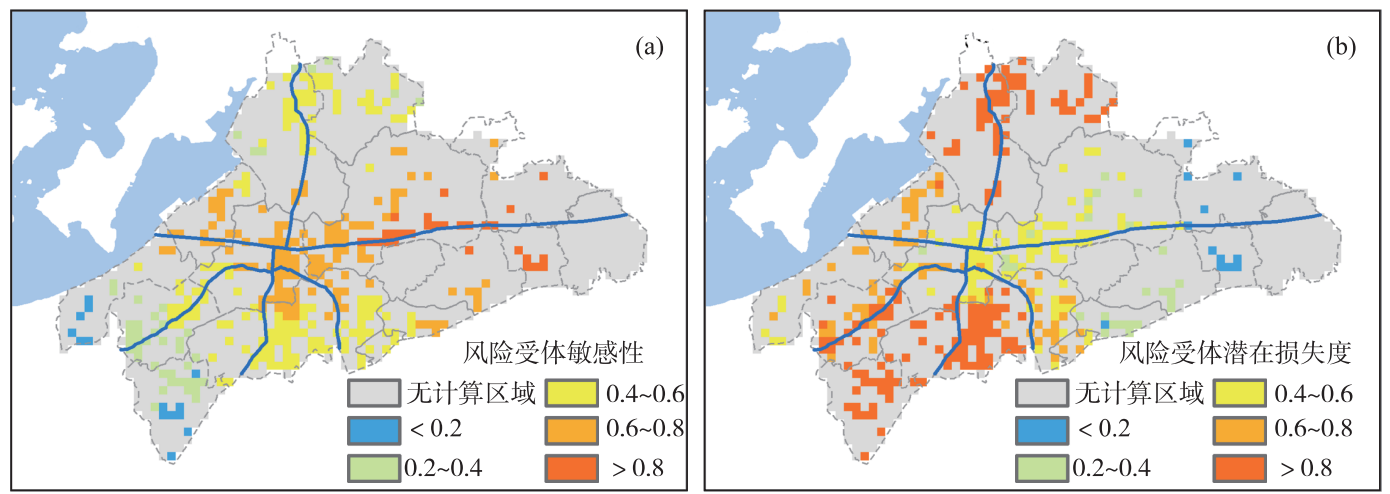

图 3 太浦河周边区域突发水污染风险受体敏感性 $(\mathrm{a})$ 与潜在损失度 $(b)$

Fig.3 Sensitivity (a) and potential loss (b) of risk receptor for water pollution accident in Taipu River region 网格.

3) 化学需氧量与氨氮: 大型工业企业与污水处理厂主要分布在盛泽镇, 盛泽镇的化学需氧量与氨氮风 险指数较高; 王江泾镇由于工业企业与污水处理厂的数量较多, 其化学需氧量与氨氮风险指数也较高; 横扇 镇、天凝镇、平望镇和黎里镇的工业企业数量较少, 但由于与太浦河的空间输移距离较小, 其化学需氧量与 氨氮风险指数也有高值网格零星分布; 同里镇、松陵镇、桃源镇、震泽镇、七都镇与太浦河的空间输移距离较 大, 并且与嘉善水源地、青浦水源地的距离均较大, 因此, 其化学需氧量与氨氮风险指数并未呈连片分布.

4) 锑与重金属铬: 锑与重金属铬的风险指数均呈现零星分布的特征, 主要受工业企业性质决定. 锑来源 于涉锑的纺织工业企业, 集中于太浦河南部的盛泽镇、天凝镇、王江泾镇, 该区域的锑风险指数较大, 其他区 域有少量涉锑企业分布; 重金属铬来源于电镀企业的工业废水排放, 总体分布面积不大, 并且规模较小, 集 中于太浦河北部的同里镇,导致该区域的重金属铬风险指数较大.

\section{3 综合风险}

太浦河污染源风险评估范围的突发水污染综合风险指数具有显著区域差异, 中度风险以上的区域呈斑 块状分布 (图 5). IV 级与 $V$ 级突发水污染综合风险区域面积共 $22 \mathrm{~km}^{2}$, 占太浦河污染源风险评估范围总面 积的 $1.4 \%$. 它们空间上集中于盛泽镇, 零星分布于同里镇东部、平望镇局部和黎里镇沿太浦河岸区域. 盛泽 镇有大型的纺织印染与助剂企业和污水处理厂, 涉锑生产单位众多, 且沿澜溪塘分布有危险化学品仓库和 码头, 使多种污染物的源强较大, 对下游的风险受体潜在损失度大, 成为突发水污染的高风险区域. 黎里镇 在沿太浦河岸区域有密集的加油站和危险化学品仓库及专用码头分布, 并布局有涉铬排放工业企业, 因距 离太浦河和水源地较近, 可对太浦河及其下游造成直接的污染危害, 是突发水污染高风险发生区. 同里镇东 部分布有大型的危险化学品仓库、工业企业和污水处理厂, 其重金属铬源强较高, 下游经济潜在损失度高, 是风险防控的重点区域.

III级突发水污染综合风险区域面积较大, 总面积 $41 \mathrm{~km}^{2}$, 占太浦河污染源风险评估范围总面积的 $2.5 \%$, 主要集中在平望镇和松陵镇. 平望镇是该区域的交通枢纽节点, 分布有大量的加油站、码头、危险化学品仓 库等污染源, 各类污染源强指数偏高, 且距离太浦河较近, 水源地敏感性高. 松陵镇也分布有一定量的工业 企业和污水处理厂,且加油站较多,下游潜在损失度大, 风险等级较高.

II 级突发水污染综合风险区域较大, 总面积为 $286 \mathrm{~km}^{2}$, 占太浦河污染源风险评估范围总面积的 $17.6 \%$, 主要集中在桃源镇、震泽镇、姚庄镇、金泽镇等地. 桃源镇与震泽镇尽管有不少工业企业与污水处理厂、危险 化学品仓库、码头分布, 但到太浦河的空间输移距离均较远, 并且与水源地距离均较远, 因此所在区域的综 合风险等级呈现中低风险等级. 姚庄、金泽镇尽管存在少量到太浦河的空间输移距离较近的工业企业, 但由 于工业企业规模不大,所在区域的综合风险等级呈现中度风险以下等级.

I 级突发水污染综合风险区域面积最大 $\left(1275 \mathrm{~km}^{2}\right)$, 该区域基本无加油站、危险化学品仓库、码头、工 

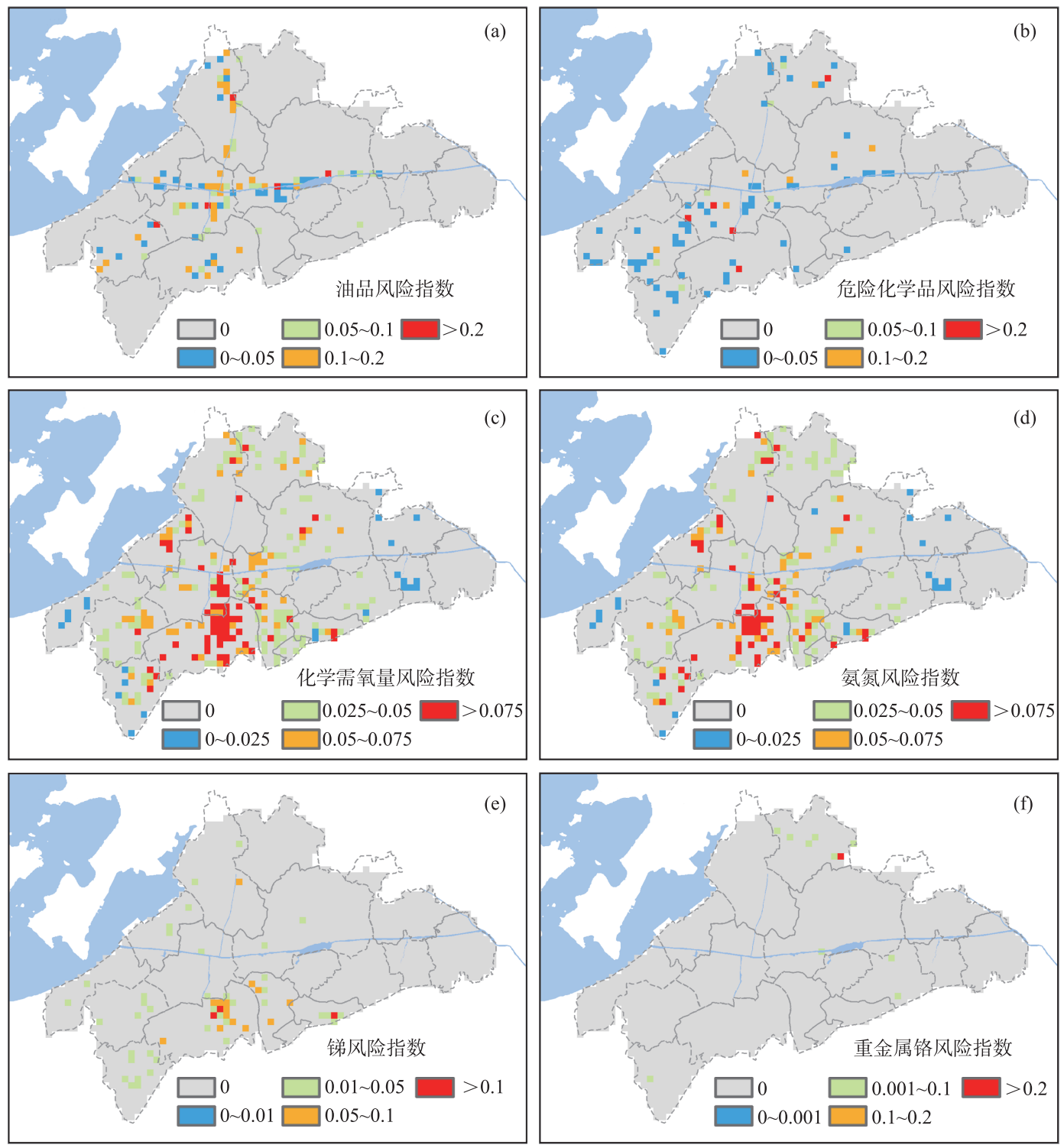

图 4 太浦河污染源风险评估范围的单一污染物风险指数:

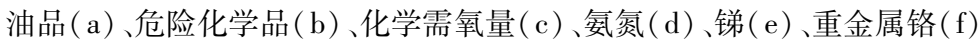

Fig.4 Pollutants' risk value for water pollution accident in Taipu River region: (a) Oil;

(b) Hazardous chemicals; (c) Chemical oxygen demand; (d) Ammonium; (e) Antimony ; (f) Chromium

业企业、污水处理厂, 突发水污染风险极低.

\section{4 风险评估合理性与不确定性}

本研究案例的风险评估综合考虑了潜在风险源危害性、风险受体敏感性、风险受体潜在损失度,构建的 评估指标体系可以反映太浦河周边区域的突发水污染风险; 在风险受体敏感性计算中, 量化了风险源到太 浦河与水源地的空间输移距离, 反映了平原河网区的污染物输移特征, 符合太浦河突发水污染风险的管理 需求, 研究方法可为类似研究区的突发水污染风险评估提供参考.

尽管风险评估方法科学合理,但评估过程中仍存在不少需要改进之处,例如: (1) 突发水污染风险评估 


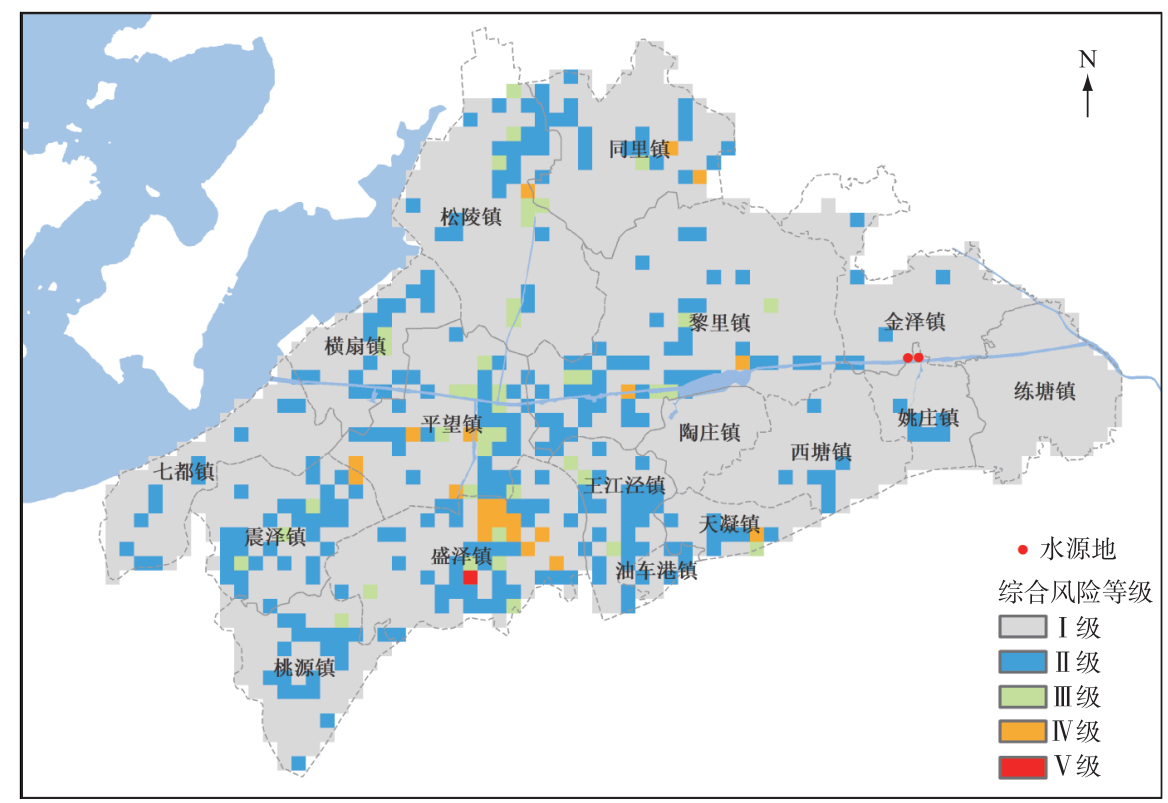

图 5 太浦河污染源风险评估范围的综合风险等级分布

Fig.5 Spatial pattern of risk levels for water pollution accident in Taipu River region

中涉及到系列权重系数(公式(8)), 本研究采用专家咨询方法确定, 具有一定的主观性, 需要在评估实践中 不断论证并优化, 提高权重系数的可信度; (2) 本研究采用风险源到太浦河的输移距离表征风险受体敏感 性, 而现实中污染物输移的影响要素除了空间距离外, 还包括了河道地形与水文条件等要素, 因此在后续工 作中, 可以考虑在突发水污染风险评估中耦合河道水动力一水质数值模型, 例如 MIKE21、EFDC 等模型, 可 以实现污染物在河道空间输移过程的精细化模拟 ${ }^{[21-22]}$; (3) 本研究污染源包括工业企业、污水处理厂、加油 站、码头、危险化学品仓库, 但研究区域内仍然存在其他污染源 (如船舶污染源), 有待在进一步研究中不断 完善污染源信息.

\section{4 结论}

太浦河周边区域的突发水污染综合风险具有显著的区域差异性, 高风险 ( IV 级与 V 级) 区呈现片状或斑 块状分布, 主要包括大型污水处理厂区域、大型工业企业区域、加油站和危险化学品仓库集中分布区、太浦 河沿岸工业企业区域、水源地周边工业企业区域, 总面积为 $22 \mathrm{~km}^{2}$, 占太浦河污染源风险评估范围总面积的 $1.4 \%$. 太浦河周边区域的突发水污染事件风险防控的重点区域包括:大型污水处理厂与工业企业集中分布 的区域,加油站和危险化学品仓库及专用码头集中分布的区域, 上述区域发生突发水污染事件时, 可对太浦 河及周边水体造成严重影响; 太浦河沿岸区域与水源地周边工业企业规模较小,但与太浦河距离很近,也应 引起足够重视.

\section{5 参考文献}

[ 1 ] Ding F, Huang LY, Wang R et al. Water pollution emergencies in China, 2004-2015: monitoring data analysis. China Journal of Public Health, 2017, 33(1): 59-62. [丁凡, 黄立勇, 王锐等. 中国 2004-2015 年突发水污染事件监测数 据分析. 中国公共卫生, 2017, 33(1): 59-62.]

[ 2 ] Wang Y, Wu SB, Wang CL et al. Emergency monitoring and analysis for "7.21" water contamination incident in Fujiang River. Yangtze River, 2012, 43(12) : 64-67. [王云, 吴树宝, 王春雷等. “7.21”涪江突发水污染事件应急监测分析. 人民长江, $2012, \mathbf{4 3}(12):$ 64-67.]

[ 3 ] Yang MX, Jie JC, Li JX et al. The research of sudden water pollution simulation based on 3S integration. China Water Re- 
sources, 2011, 11(1): 12-17. [杨明祥, 解建仓, 李建勋等. 基于 $3 \mathrm{~S}$ 集成的突发水污染模拟研究. 中国水利, $2011,11(1): 12-17$.

[ 4 ] Zheng T, Wang YQ, Wang P. Research status and problems of the risk assessment system of sudden water pollution accidents. China Population, Resources and Environment, 2016, 26(11): 83-87. [郑肜, 王亚琼, 王鹏. 突发水污染事故 风险评估体系的研究现状与问题. 中国人口・资源与环境, 2016, 26(11) : 83-87.]

[ 5 ] Yao H, Zhang T, Liu B et al. Analysis of surface water pollution accidents in China: Characteristics and lessons for risk management. Environmental Management, 2016, 57(4) : 868-878.

[ 6 ] Tao Y, Lei K, Xia JX. Main hydrodynamic factors identification for pollutant transport in sudden water pollution accident in Shenzhen Bay. Advances in Water Science, 2017, 28(6): 888-897. [陶亚, 雷坤, 夏建新. 突发水污染事故中污染 物输移主导水动力识别——以深圳湾为例. 水科学进展, 2017, 28(6):888-897.]

[ 7 ] Wang JB, Lei XH, Liao WH et al. Source identification for river sudden water contamination based on coupled probability density function method. Journal of Hydraulic Engineering, 2015, 46(11) : 1280-1289. [王家彪, 雷晓辉, 廖卫红等. 基于耦合概率密度方法的河渠突发水污染溯源. 水利学报, 2015, 46(11) : 1280-1289.]

[ 8 ] Hou D, Ge X, Huang P et al. A real-time, dynamic early-warning model based on uncertainty analysis and risk assessment for sudden water pollution accidents. Environmental Science and Pollution Research, 2014, 21(14) : 8878-8892.

[ 9 ] Tao Y, Ren HT, Xia JX. Effect analysis of different emergency measures for accidental water pollution. Journal of Basic Science and Engineering, 2013, 21(2) : 203-213. [ 陶亚, 任华堂, 夏建新. 突发水污染事故不同应对措施处置效果 模拟. 应用基础与工程科学学报, 2013, 21(2) : 203-213.]

[10] Zhang B, Qin Y, Huang M et al. SD-GIS-based temporal-spatial simulation of water quality in sudden water pollution accidents. Computers \& Geosciences, 2011, 37(7): 874-882.

[11] Grifoll M, Jordà G, Espino M et al. A management system for accidental water pollution risk in a harbour: The Barcelona case study. Journal of Marine Systems, 2011, 88(1) : 60-73.

[12] van Mazijk A. Modelling the effects of groyne fields on the transport of dissolved matter within the Rhine Alarm-Model. Journal of Hydrology, 2002, 264( 1) : 213-229.

[13] Fang Y, Zhang D, Lei X et al. Emergency control strategy for sudden water pollution accident in the main channel of middle route of South-to-North water diversion project. South-to-North Water Transfers and Water Science \& Technology, 2014, 12(2) : 133-136. [房彦梅, 张大伟, 雷晓辉等. 南水北调中线干渠突发水污染事故应急控制策略. 南水北调与水 利科技, 2014, 12(2): 133-136.]

[14] Zhang ZJ, Ye M, Zhang K. Watershed-scale environmental risk assessment for typical accidental water pollution accidents in the east of Guangdong Province. Journal of Safety and Environment, 2018, 18(4): 1532-1537. [张志娇, 叶脉, 张 珂. 广东省典型流域突发水污染事件风险评估技术及其应用. 安全与环境学报, 2018, 18(4) : 1532-1537.]

[15] Xiao Y, Huang SL, Kong FQ et al. Risk zoning and assessment of watershed sudden water pollution incidents based on control units of the water function areas. Journal of Catastrophology, 2018, 33(3): 222-228. [肖瑶, 黄岁樑, 孔凡青 等. 基于水功能区控制单元的流域突发性水污染事件风险评价区划及其应用. 灾害学, 2018, 33(3): 222-228.]

[16] Lian JJ, Sun XZ, Ma C et al. Risk assessment and emergency dispatching of sudden water pollution incident in reservoir. Journal of Tianjin University: Science and Technology, 2017, 50(10) : 1005-1010. [练继建, 孙萧仲, 马超等. 水库突 发水污染事件风险评价及应急调度方案研究. 天津大学学报: 自然科学与工程技术版, 2017, 50(10): 1005-1010.]

[17] Jin CL, Wang YX, Gong L. Risk assessment of sudden water pollution in Lanzhou section of Yellow River based on fuzzy hierarchy evaluation method. Journal of Safety and Environment, 2018, 18(1) : 363-368. [靳春玲, 王运金金, 贡力. 基于 模糊层次评价法的黄河兰州段突发水污染风险评价. 安全与环境学报, 2018, 18(1) : 363-368.]

[18] Dong L, Liu J, Du X et al. Simulation-based risk analysis of water pollution accidents combining multi-stressors and multireceptors in a coastal watershed. Ecological Indicators, 2018, 92: 161-170.

[19] Peng J, Song Y, Yuan P et al. An novel identification method of the environmental risk sources for surface water pollution accidents in chemical industrial parks. Journal of Environmental Sciences, 2013, 25(7) : 1441-1449.

[20] Xu Y, Gao JF, Zhao JH et al. The research progress and prospect of watershed ecological risk assessment. Acta Ecologica Sinica, 2012, 32(1) : 1-9. [许妍, 高俊峰, 赵家虎等. 流域生态风险评价研究进展. 生态学报, 2012, 32(1): 1-9.]

[21] Jeong S, Yeon K, Hur Y et al. Salinity intrusion characteristics analysis using EFDC model in the downstream of Geum River. Journal of Environmental Sciences, 2010, 22(6) : 934-939.

[22] Bae S, Seo D. Analysis and modeling of algal blooms in the Nakdong River, Korea. Ecological Modelling, 2018 , 37: 253-263. 